\title{
Feng Shui: A Comprehensive Review of its Effectiveness Based on Evaluation Studies
}

\author{
Špela Kryžanowski
}

Assist. Prof. PhD, Arch.

Faculty of Design

Associated Member of the University of Primorska

Slovenia

\begin{abstract}
After five decades of its presence in the Western European space, the architectural profession, regardless of the popularity of feng shui, has never systematically declared itself about this phenomenon. This is a professional problem. It is equally absurd to dismiss feng shui as a bunch of superstitious nonsense without properly scientifically researching it, as well as its detailed study following all Western science standards, without asking, at least once, whether the fengshui recommendations have the effect they promise, and if so, which and why. To answer this question an in-depth analyses of scientific articles on feng shui was performed. Evaluation studies found were divided into three groups: comparative studies where the effectiveness of fengshui's recommendations is not directly verified by field research, but compared with findings in other areas of science; field experimental studies that examine the actual effectiveness of selected feng shui recommendations, through a real or virtual environment, engaging participants and sometimes a control protocol and studies of living quality evaluation systems with feng shui recommendations. Based on the results of the studies analysed it can be concluded, that between the feng shui school of form, environmental psychology and sustainable design principles there are certain similarities, which some researchers confirm with a higher or a lower degree of correlation and statistical significance. On the other side, one of the fundamental concepts of feng shui, namely the concept of life energy qi, remains poorly researched. The conclusion is, that the greatest potential of feng shui for contemporary architecture is not so much in the practical application of its techniques and recommendations, as much of this is already included in everyday design practise, but in its philosophical and conceptual foundations. They can encourage architects to re-think spatial concepts and, if necessary, to change established spatial paradigms.
\end{abstract}

Key Words: Feng Shui, Scientific Evaluation, Comparative Studies, Experimental Studies.

\section{INTRODUCTION - CHALLENGES FOR FENG SHUI EVALUATION}

Feng shui is the traditional Chinese art of designing environments and physical spaces. It is part of a multi-millennial tradition. In the West, it has become more known in the last three decades of the 20th century and achieved its peak of popularity around the turn of the millennium. This was beautifully described by the president of the Hamburg Architecture Chamber with the words ${ }^{\mathrm{i}}$ : 'When we offer a seminar on construction, a dozen architects come, when we report on feng shui, a hundred of them come.' As we will see below, the architectural profession, regardless of the popularity of feng shui, has never systematically declared itself about this phenomenon. So even after 5 decades of its presence in the Western European space, what architects should think about the use of feng shui in design, is still left to the personal discretion of each professional. The findings suggest that even in the modern Asian space, where feng shui is part of the tradition, it is not fundamentally different. I believe that this is a professional problem. The architectural profession has to define phenomena that may affect the design and, consequently, the quality of the built environment. Science has to define all phenomena that have a great social, economic and personal influence as this is the case with feng shui. Like any other social phenomenon, it must first be systematically analysed and then evaluated. It is equally absurd to dismiss feng shui as a bunch of superstitious nonsense without properly scientifically researching it, as well as its detailed study following all Western science standards, without asking, at least once, whether the fengshui recommendations have the effect they promise, and if so, which and why. Architectural experiences acquired in this way, which prove to be able to have a positive impact on the design of the built space, can reasonably be incorporated into the doctrine of contemporary architectural design. The use of concepts that do not withstand the credibility test can then be expertly advised against. The absence of an indepth architectural valuation of feng shui marvels all the more so, at the fact, that feng shui represents a multi-million- business that has a direct impact on real estate markets, buildings and urban planning ${ }^{\text {ii. }}$ It affects the position of the building in the 
environment and physically transforms the design of the building's floor plan or its appearance. It, therefore, affects the direct user experience of the physical space. However, the absence of a critical evaluation of feng shui is not specific only to the architectural profession. As will be shown in the review of the contributions below, that this kind of evaluation of feng shui is malnourished in all areas and all cultural environments. The reasons why a critical evaluation of feng shui remained ignored are many and their nature is complex. Some of the most obvious dilemmas posed to a Western architect who would like to assess the effectiveness of feng shui in more detail are set out below.

Firstly: One of the first problems the researcher encounters, is the definition or systematization of the subject of the research. Feng shui techniques are numerous, varied and unsystematized. There is no orderly collection about which the most exposed protagonists of the traditional feng shui would agree that it represents a credible representation of what is meant as traditional feng shui. So how can we systematically investigate without a unified and coherent base? How can we investigate if individual derivatives of techniques are sometimes contradictory or give different results? The reasons for this can be found in the development of feng shui. Techniques have changed and been upgraded throughout history. Feng shui as we know it today is said to have formed during the Song dynasty. (960-1279 N.C.). Historical texts show that there have been several competing schools in China's divination history. In the end, two major schools that draw on neo-Confucian philosophy prevail, the school of form and the compass schoolii. At the same time, a high factor of the subjectivity of the use of feng shui knowledge in practice should be taken into account in some way. Although feng shui may seem unambiguous to the untrained eye, the whole tradition of feng shui is historically based on the subjectivity of an individual fengshui practitioner or master.

Secondly: How should the evaluation analysis of feng shui take into account modern versions that occur in the Western world? When transferred to other cultural environments, feng shui transformed. Paton ${ }^{\text {iv }}$ points out that when it comes to the transfer of Chinese concepts to another cultural environment (for example, Western European), it is about a typical summary of only those parts that correspond to the cultural context into which they are transferred. Modern Western feng shui is thus modified on several levels ${ }^{\mathrm{v}}$. First, everything related to the formation of graves (yin feng shui) is eliminated and this, according to the fengshui master of the 65 th generation of Taiwanese feng shui practitioners He Jinzong, represents as much as $50 \%$ of what plays a decisive role in the traditional feng shui ${ }^{\mathrm{vi}}$. In transmission, everything related to the action of ghosts (ancestors, gods, etc.) is eliminated. In modern Western feng shui, only techniques involving impersonal cosmological forces (e.g. the influence of stars in Flying Stars) remain. The third big change is that feng shui starts to focus mainly on interior design and no longer on the position of the building in relation to the landscape. The fourth big change is that feng shui begins to connect with modern paradigms of ecology, environment and design. The basic philosophical concepts also begin to be interpreted in a modern way of mechanistic thinking, e.g. qi is associated with electromagnetic forces, it is described as an energy field, etc. Qi phenomenon is seen as separate from human co-engagement, which is contrary to the comprehensive traditional Chinese approach, where the fields of nature, society and individual are closely intertwined and resonantly integrated ${ }^{\text {vii }}$. It is also worth noting that much of the feng shui techniques published in Western literature are part of the so-called commercial feng shui, which is not recognised at all by traditional teachers ${ }^{\text {viii }}$. If the feng shui evaluation survey is based on such a technique, the question is, what do such results show?

Thirdly An additional problem is the original sources written in Chinese characters and language that most Western researchers do not know and therefore depend on indirect translations. Few architects also have the sinological knowledge and rare sinologists have exhaustive architectural knowledge required to translate the design of space-related texts. Another challenge is the ambiguity of Chinese characters. Many expressions in Chinese tradition (and also in feng shui) have a multifaceted and specific meaning and there are no corresponding synonyms for them at all ${ }^{\mathrm{ix}}$. At the same time, feng shui concepts remain unexplained in many Chinese dictionaries and encyclopedias. An additional obstacle is the ignorance of the cultural-historical framework in which feng shui was born. Most architects, who want to explore feng shui in-depth in one of the Western European languages, are thus limited either to scientific papers on feng shui, written by authors of other disciplines and consequently interested in other aspects as architects, or to popular feng shui manuals, written by either feng shui practitioners themselves or writers of other professions in combination with feng shui practitioners. None of them generally has an architectural education. Two of the few exceptions are Lip (published one of the first feng shui manuals in $1979^{x}$ ) and Bramble ${ }^{x i}$. I would argue that architectural education is extremely important when reading feng shui recommendations. With this kind of knowledge, it is quite possible to exclude from feng shui all those recommendations and doctrines that are already part of modern design practice, where knowledge of feng shui does not play an essential role.

Fourthly: The scientific proofing or rejection of the fundamental concept of feng shui, namely the existence of life energy qi, is problematic. Among the protagonists of scientific proof of the existence of qi are the known qigong practitioner Yan ${ }^{\text {xii }}$ and $\mathrm{Lu}^{\text {xiii }}$, a physicist whose research confirms the physical existence of an external qi and shows that man can influence substances such as water, DNA or atomic nucleus without physical contact. On the other hand, there are critics of this research ${ }^{\text {xiv }}$ who argue that the existence of qi has yet to be proven. This is usually also one of the reasons that some $\operatorname{critics}^{\mathrm{xv}}$ define feng shui as pseudoscience. 
Fifthly: The main problem in the analytical evaluation of feng shui, which is of particular interest to the architectural profession, is certainly the verification of its functional effectiveness, i.e. isolation and analysis of feng shui effects. So how do you set up a scientific protocol, so that it can be argued, that the effect that the results show is the effect of feng shui recommendations, and not of other factors? And if we can do that, how do we eliminate the placebo effect? Despite all these problems, some researchers decided to face the challenge. Unfortunately, they are not many. That is why the central part of the article presents all the identified articles that directly or indirectly deal with the evaluation of feng shui concepts or recommendations.

\section{MATERIALS AND METHODS}

The following review is grounded in previous research on feng shui ${ }^{\text {xvi }}$, where, among other things, it was researched which techniques of traditional feng shui, published in Western - European literature of the past four decades, have been used in a same way by different practitioners. One of the parallel findings was that none of the feng shui manuals provides any scientific evidence for the effectiveness of the recommendations presented. Which prompted research to find an answer, of whether the architects are even seriously exploring feng shui in terms of evaluation and, if so, what are results? In the preview, qualitative analysis with document analysis ${ }^{\text {xvii }}$ and desk survey ${ }^{\text {xvii }}$ was used. A systematic and comprehensive review of scientific papers published in professional books, journals, reports and newspapers ${ }^{\text {xix }}$ was carried out, using the terms 'feng shui' and 'Chinese Geomancy'. The search included the period up to 2020 in the Springer, JSTOR, ProQuest and Google Scholar web bases. All contributions relating to feng shui were included in the first review. From the set of approx. 3,000 hits approx. 300 contributions were selected, based on the criteria of authenticity, credibility and representativeness. They were examined and classified into 7 thematic groups: anthropology, urbanism and architecture, sustainability, economics, health, modern Chinese scientific research of feng shui and evaluation studies. To formulate the answer to the research question, the evaluation studies presented below have shown to be essential.

\subsection{A REVIEW OF FENG SHUI EVALUATION ARTICLES}

Historical (historical) or descriptive (descriptive) scientific research methods are generally used in the study of the feng shui. Experimental evaluation research of feng shui is rare and mainly focuses on an individual fengshui set or school. Identified evaluation studies can be divided into three groups. The first covers comparative studies where the effectiveness of fengshui's recommendations is not directly verified by field research, but compared with findings in other areas of science, specifically environmental psychology and sustainability. The second group comprises of field experimental studies that examine the actual effectiveness of selected feng shui recommendations, through a real or virtual environment, usually engaging participants and sometimes also a control protocol. The third group presents examples of living quality evaluation systems, in which the feng shui recommendations could be systemically included.

\subsection{COMPARATIVE STUDIES WITH FOCUS ON ENVIRONMENTAL PSYCHOLOGY}

The paper Geomancy Theories and Behaviour Psychology by $\mathrm{Xu}^{\mathrm{xx}}$ is one of the first to analyze the theoretical starting points of feng shui and to compare them to the fundamental human needs of behavioural psychology: survival, safety, sexuality and development. The author notes that the key findings of feng shui theory could be used in the creation of architectural solutions. The Feng Shui and Environmental Psychology: A Critical Comparison study by Bonaiuto et al. ${ }^{\text {xi }}$ also takes two psychological characteristics of space as the central subject of the analysis (the element of restorativeness and the element of control). First, it presents the fundamental characteristics of environmental psychology and feng shui, noting that many lessons in environmental psychology are embedded in the design recommendations of feng shui. The results of the study also confirm that both, the element of restorativeness (e.g. the view of nature, which reduces psychological fatigue and stress) as well as the element of control (or our level of power over the environment), in both systems are recognised as very important environmental characteristics. The authors conclude that there are points of contact between environmental psychology and feng shui. Compass school is not mentioned in this study. A further comparative analysis by the author ${ }^{x x i i}$ seeks to answer the research question of whether the selected 118 recommendations of the feng shui school of form are aligned with the recommendations of Alexander's pattern language and selected environmental psychology findings. The results support the research question and show that $34 \%$ of the recommendations (40) are aligned with the pattern language and that $45 \%$ (53) are fully or partially aligned with the findings of environmental psychology. In total more than half of the recommendations (57\%) are consistent with one or other knowledge system. There are 27 recommendations (23\%) which are double-consistent, most of which are associated with the feng shui scheme of five animals, the importance of the presence of water and natural light in the living environment and the importance of the main entrance. The bulk of the recommendations which remain unreferenced are linked to the Chinese concept of life energy qi.

\subsection{COMPARATIVE STUDIES WITH A FOCUS ON SUSTAINABILITY}

In addition to substantial anthropological research, feng shui in conjunction with modern sustainable concepts is certainly one of the more focused-on research areas. This is understandable since there are many common points between the principles of feng 
shui and sustainable concepts. Yoon ${ }^{\text {xiii }}$ is the first to formally address this issue in the 1990s. Contributions in this field that focus on concrete physical spaces can be divided into two groups. The first group examines traditional facilities and arrangements built per the recommendations of feng shui and, based on the data obtained, seeks to find further, up to now ignored, useful aspects for improving existing sustainable design practice. Shin and Lim $^{\text {xxiv }}$ analyse traditional Korean houses built according to local feng shui. The researchers focus on the elements of passivity, which could then also be used in the design of modern passive houses. Lau at al. ${ }^{\mathrm{xxv}}$ in The Sustainable Design and Its Simplest Form, also present the results of field analysis of traditional houses from Hakka village in Fujian Province, China. The peculiarity of these houses is that they are made of the earth and have round or rectangular floor plans. The researchers also use feng shui to help them understand and link the study's results to modern sustainable concepts. The Ecological Design Concept of Traditional Architecture ${ }^{x x v i}$ provides a general overview and comparison between traditional Chinese architecture and modern sustainability requirements. Choe and Han ${ }^{\text {xxvii }}$ are also checking how the feng shui recommendations align the Korean sustainable concepts. Using 3d mapping, they analyse a set of ideal locations from the Korean version of feng shui, and conclude, that based on the results, fengshui recommendations could be integrated into modern architectural systems.

The second group of articles analyses objects or arrangements built according to modern sustainability principles and which are subsequently checked by the authors for feng shui. The purpose of these analyses is to show that the chosen feng shui recommendations and the modern sustainable concepts overlap to a large extent. Mak is the most active in studying sustainable office buildings compared to feng shui principles. He presents his findings in the contributions Sustainable Design and Feng Shui: A Case Study of an Office Building in Sydney ${ }^{\text {xxiii }}$, Feng Shui: A Chinese Perspective of Sustainability ${ }^{\text {xix }}$ and An Empirical Study of Modern Sustainable Office Buildings in Sydney from the Feng shui Perspective ${ }^{x x x}$. In the latter, Mak focuses on the similarities between the principles of sustainable architecture and the chosen recommendations of feng shui by analyzing a group of 31 contemporary sustainable business houses in Sydney from the perspective of both. For evaluation, the author, drawing on Dong $^{\text {xxxi }}$, summarises 5 fundamental sustainability principles and 5 fundamental recommendations related to feng shui. For feng shui, it is possible to receive $5 \times 2$ points (max. 10 points), all based on actual site visit. To assess sustainable aspects, the existing Australian Green Star sustainability rating system is used. The comparative analysis shows that a building with a higher average Green Star score also has a higher feng shui average score (correlation coefficient is 0.857 ). And that both approaches have similar goals in terms of sustainability. The author concludes that feng shui recommendations could also improve the efficiency of sustainable building design. Similarly, Mak and Hui ${ }^{\text {xxii }}$ are also analysing the modern West Kowloon railway station in Hong Kong (built 2018). They note that most of the five key sustainability principles used in the construction of the railway station also meet or support the five fundamental feng shui principles. The study by Octavie et al. ${ }^{\text {xxiii }}$ focuses on a house in Jakarta. Authors first examine the extent to which the house complies with the selected 35 feng shui recommendations (summarized by Spear ${ }^{\text {xxxiv }}$, which partly include commercial feng shui). In further analysis, they conclude that fengshui design has a partially neutral and partly positive impact on adherence to sustainability principles.

\subsection{EXPERIMENTAL FIELD STUDIES}

School of form is the main focus of experimental studies, as well. As many as half of them deal with the position of the building in the wider environment, and half focus on the interior. Han and Amita in An Empirical Study of Feng shui and Landscape xxx $^{-}$ select five tombs in Taiwan, which, according to the master's assessment, have good feng shui and correspond to the model of five animals of the school of form. Then they analyse the locations with modern landscape-psychological parameters. Locations are also assessed by participants via photos. The results of the study show that locations with good feng shui are also rated positively in terms of aesthetic and psychological characteristics. Similarly, Han ${ }^{\text {xxxi }}$ undertakes a later study to prove that landscapes that are well-judged for feng shui are also more liked than landscapes with poor feng shui. Although the results support the hypothesis, the difference between landscapes with good and bad feng shui is not statistically significant. Since the position of the grave for feng shui is very important $\mathrm{Um}^{\mathrm{xxxvii}}$ explores whether the reality reflects the theory. For the location of 5549 graves, he provides an analysis of the relationship between grave density and selected school of form parameters. Using Geographic Information System (GIS) technology and spatial regression modelling, he finds that the most influential parameter for the density of the graves analysed was solar radiation. Contrary to feng shui theory the sloping of the terrain, aspect and southern orientation do not prove to be the dominant determining factors in grave density. The author sums up that choosing a plot is more about avoiding shady positions than finding the ideal landform location. The subject of urban and landscape quality research from the point of view of feng shui is not limited to Asian locations. The study titled Feng shui as a Site Design Tool: Assessing Conditions of Human Comfort in Urban Places ${ }^{\text {xxviii }}$ presents a qualitative assessment of 20 existing open urban spaces in various cities in Arizona (U.S.) in terms of feng shui school of form recommendations and in the light of modern recommendations for the design of open spaces. The results, although obtained on a small sample, suggest that urban spaces well-rated for feng shui are also well-rated in terms of the recommendations of modern design. The author notes that there is a high degree of similarity between the two groups of parameters and that it is relatively easy to spill feng shui recommendations over into modern design. $\mathrm{Mak}^{\mathrm{and}} \mathrm{Ng}^{\mathrm{xxxix}}$ carry out a combined urban-interior study. It is an empirical survey with architects from Hong Kong and Sydney, which examines whether the preferences of modern architects for choosing the best location for the building and the best design arrangement for the lounge are in line with the recommendations of the feng shui school of form. The results show that a convincing majority of architects 
choose a scheme that is also best in terms of feng shui, with the nationality showing no significant difference. Similarly, evaluation of architects' lounge sketches shows considerable consistency with the school of form's core recommendations. The average value for Sydney architects' sketch is 7.86 (from max. 10 points) and Hong Kong's 7.80.

A further three experimental studies focus on the interior, specifically on bedrooms. A detailed empirical analysis of the design of modern bedrooms compared to the recommendations of the feng shui school of form can be found in the paper Are Feng shui Bedroom Rules Practical from the Architectural Perspective? ? $^{\mathrm{xl}}$ Through structured interviews with 16 architects and an analysis of their 30 best bedroom arrangements, the authors conclude that the schemes transmitted are more or less consistent with feng shui recommendations (the average estimate is 4.13 out of max. 5 points). As the most important element of the design is the position of the bed along a solid, preferably longest, wall. The headboard position under the window is undesirable. The bathroom space is separate from the bedroom. The relationship between the position of the bed and the bathroom wall is not particularly important to the architect, nor is compass orientation, but both parameters are important in feng shui. 16 architects are of Chinese origin, but nationality doesn't show as significant. Based on the study's results, the authors conclude that fengshui recommendations are more than just superstitions and that they can be successfully used in bedroom design. Bedroom design and school of form are also the topics of So and $\mathrm{Lu}^{\mathrm{xli}}$ research, which uses Computational Fluid Dynamics (CFD) modelling to check whether any verification can be found for the recommendation, that a bedroom should be away from bathrooms, toilets and kitchens. One of the study's presumptions is that a good airflow around the apartment will also indicate a good flow of life force qi. The air current simulation is designed for a typical Hong Kong floor plan, for four different combinations of door and window openness, and winds coming from four cardinal directions. The eastern wind turns out to be the worst because it brings bad air from the bathrooms and kitchen to the living areas and bedrooms. The authors summarise that the simulations verify the rule that the bedroom should not be near the bathroom due to possible incursions of bad air and that the toilet sit-covers should always be closed. An experimental study as part of the $\mathrm{PhD}$ dissertation ${ }^{\text {xlii }}$ is also researching the link between sleep and feng shui. It examines whether the use of feng shui recommendations through the modern instrumental bio-communication can influence the perceived quality of sleep, general well-being and health. The study lasts for 4 months and involves 134 participants. Selected recommendations are sent remotely to photos of the bedrooms of participants using the Quantec system. Participants are anonymised and divided into three groups, following the double-blind protocol. The first group is receiving feng shui support during the entire research, the second group is receiving it for the last two months, and the third group is acting as a control. Data are obtained via self-assessment questionnaires sent by e-mail every 10 days and statistically treated with the $\mathrm{R}$ environment (through linear mixed models with variables: feng shui, stress, age and bedroom quality assessment). The feng shui variable (at a 95\% confidence interval) shows as highly statistically relevant $(\mathrm{p}<0.001)$ and has an impact on better sleep quality (the value rises by +0.36 on scale $1-5$ within 120 days). The assessment of general well-being shows a high statistical relevance $(p<0.001)$ for the combination of variables feng shui and bedroom quality assessment. A closer analysis shows that positive support of feng shui is highest for stress-free participants who poorly assess the quality of their bedroom. The results confirm that the feng shui recommendations can have a statistically relevant effect on self-assessed sleep and well-being. ${ }^{\text {xlii }}$

The last three field studies analyse interior public spaces. A pilot study by Poulston and Bennett ${ }^{\text {xliv }}$ explores the link between good feng shui and business success. The authors first analyze eight hotel lobbies for the school of form, with recommendations grouped into 20 criteria (using lay feng shui literature). A parallel economic analysis of the hotel's performance is carried out through a structured interview with managers. The results show that six out of eight hotels have a high similarity between the hotel's performance and feng shui assessment and suggest that hotels with good feng shui are also more successful. The drawback of the study is the small sample size and the subjectivity of the economic performance, which is obtained without factual fin ancial analyses. It is particularly interesting to explore the effects of feng shui recommendations in health settings. We already know from the results of psychological research ${ }^{\mathrm{xlv}}$ that the environment can have an impact on the speed and quality of health recovery. So, the aim of the study Interior effects on comfort in healthcare waiting areas ${ }^{x l v i}$ is the analyses of the possible impact waiting rooms can have on users. Participants assessed the comfort of three differently equipped waiting rooms through questionnaires before and after the health check. The researchers also analysed the overall psychophysical state of the participants on the day of the examination. The first waiting was designed by a feng shui master, the second was designed according to the doctor's wishes, and the third complied with normal waiting room standards at medical facilities in the U.S. The results, according to the MannWhitney test for physical, intellectual and emotional comfort, show that the waiting room with the best feng shui is also best rated by the participants, while the worst is the standard-shaped waiting room. The results confirm the hypothesis that the correct use of feng shui elements can raise the perceived level of comfort of space users. A peculiarity of this study is that the school of compass was used, more specifically feng shui time calculation (Flying star) and a commercial bagua of living areas. The latest study of health care environment is carried out by Charles at al. ${ }^{x l v i}$ which analyses whether there is a statistically significant link between the positive feelings of nurses and their work environment in critical care with reference to chosen recommendations of feng shui. The study is conducted with three groups (two tests and one control) and the blind protocol. Both intensive care test rooms are pre-assessed from the perspective of feng shui, taking into account the so-called three-door bagua, which does not take into account compass orientation. The emotional state of the participants is recorded over the 2 weeks with self-evaluation questionnaires structured into nine areas, which represent nine areas of feng shui bagua. The results show no statistically significant difference (at a 95\% confidence interval) between the two differently rated feng shui intensive care rooms in relation to 
the perceived level of internal harmony of nurses. The authors conclude that the use of feng shui in medical settings is futile. In this respect, it should be noted that the analysis used a commercial three-door bagua in the study.

\subsection{FENG SHUI RECOMMENDATIONS AND SYSTEMS FOR THE EVALUATION OF QUALITY OF LIVING}

The researchers are also looking at the possibility of incorporating feng shui recommendations into contemporary systems for evaluating living quality. One such example is a study Assimilating total building performance mandates with Chinese geomancy principles and scenarios $^{\text {xlviii }}$, which examines the extent to which feng shui recommendations are consistent and applicable in the Total Building Performance (TBP) evaluation model. The findings suggest that 25 of the 26 Chinese geomantic principles and 12 of 20 Chinese geomantic scenarios are significantly useful in the TBP evaluation system (at a 95\% confidence interval). This is not surprising, as both feng shui and the TBP system aim to create an environment that supports well-being. The study also points out that certain geomantic scenarios (concerning openings, building heights, trees, roads, etc.) are not applicable in all situations. Different use of the school of form recommendations is found in Chang et al. study ${ }^{\text {xlix }}$ which is about upgrading an evaluation system that uses advanced fuzzy weighted average (EFWA) algorithms. To demonstrate the usefulness of these new evaluation algorithms, the authors use a comparison of five office concepts that are more or less in compliance with the selected school of form recommendations. They differ in the layout of the furniture and the relationship of the desk to the position of doors, windows and cabinets. The study shows that by using an advanced algorithm and clearly defined feng shui criteria one can build a useful feng shui evaluation model. The results are not directly applicable as evidence for or against the effectiveness of the used school of form recommendations. It is more an example of a possible feng shui evaluation system.

\section{CONCLUSION}

What can be concluded from the evaluation research carried out on the recommendations of feng shui? The analysis of the sources from which the recommendations were drawn shows a very heterogeneous picture. Some authors clearly state which sources were used, others do not. There is a good chance that the resources used are very different in the spectrum from traditional to Westernised and commercial feng shui. In the analysis of the content of the feng shui recommendations used, the school of form prevails. Of the 17 evaluation studies that give some factual performance score, 15 analyse the school of form 3 the compass school and 3 commercial feng shui techniques. Some studies analyse several schools/ techniques at the same time. In this respect, the small number of evaluations of the compass school is very obvious. One reason is, that the recommendations of the compass school cannot be compared to any system in modern design practice. A modern architect does not have the tools to take into account the position of the stars or the owner's birthday or the compass orientation of the building in the way that feng shui understands it. The second reason may also be, that the theory of the 8 houses (also called the east and west system) which represents an important part of today's compass school, is by some researchers rated as questionably credible ${ }^{1}$. For now, we only have one study ${ }^{\text {li }}$ focused on the compass school, which suggests that the correct application of the compass school recommendations (specifically the Flying star system) can also have a positive impact on the perceived level of comfort of users. However, one study is certainly not enough to make one's professional opinion on the use of the school of compass.

The 15 studies of the school of form recommendations use different approaches. All comparative studies, the ones using environmental psychology and sustainable principles, find correlations and conclude that some of the feng shui recommendations could be included among the principles of modern design since the design results are similar. Based on two studies it can be found that the preferences of modern architects and the school of form are similar when choosing the ideal location for the building or design for open urban space. Similarly, the arrangements that are highly rated by modern architects are also highly rated by feng shui parameters. The same is shown in the analysis of traditional tombs. The focused analysis of individual rooms in the building also gives similar results: the preferred design of the lounges of modern architects is also favourable from the perspective of the feng shui school of form and hotels with good feng shui lobbies seem to be commercially more successful. Bedrooms are one of the most researched areas. The results are similar to the lounge research and show that ideal bedrooms by modern architects are largely consistent with the feng shui school of form chosen recommendations, especially the model of the five animals. And that, through feng shui recommendations, the bedroom can influence a higher self-assessment of sleep and, in part, well-being.

What about the results that don't confirm the effectiveness of the feng shui recommendations? The Han study is statistically irrelevant ${ }^{\text {lii }}$, and two are statistically relevant but with opposite effects than claimed by feng shui recommendations. It is found that feng shui graves in practice show a different picture than in theory. Which confirms, as Bruun (2003) $)^{\text {liii }}$ points out, that fengshui theory is an ideal that is often different from solutions that are then realized in practice. The other study uses one of the commercial bagua versions as a base, so its results are useless in terms of assessing traditional feng shui recommendations. The same is true, but to a lesser extent, to the other two studies by Octavia et al ${ }^{\text {liv }}$ and Bazley ${ }^{\text {lv }}$, where commercial feng shui represents only part of the examined recommendations. 
Based on these results, it can be concluded with high probability, that the effects of some of the school of form recommendations are very similar to those of modern design practice. Among the school of form, environmental psychology and sustainable design principles there are certain similarities, which some researchers confirm with a higher or a lower degree of correlation and statistical significance. This suggests that some of the feng shui recommendations work or have the effects they promise. It is obvious that traditional teachers, with the help of careful observation and philosophical insight, came to some similar conclusions as modern scientists, but they used different vocabulary and symbols than the ones that are common in the modern scientific context. The composition of the five mystical feng shui animals, which is probably the most researched among all recommendations, seems to be nothing more than a description of a spatial situation where the back aspect of the location is protected, and the front aspect opened up, so it can be easily controlled. At the same time, care is taken to have the best solar gain possible, access to drinking water, while at the same time, enough protection against the winds. This is the position of power in the environment that enabled survival, and still today, gives us a sense of security. Environmental psychologists also name it the memory of the savannah ${ }^{\text {lvi }}$. And this applies in a similar way to both the layout of houses in the landscape and the design of interior spaces. As some other authors have pointed out ${ }^{\text {lvii }}$, feng shui seems to be an ancient architectural theory, a mixture of art and science, which in its own way has managed to define some of the fundamental mechanisms of human behaviour in physical space and effective location choices (adapted to the climatic and geographical characteristics of the landscape). Each contemporary building tradition usually takes from the past the useful things and sometimes gives them new vocabulary, creating the false impression that it is about completely different approaches.

There are far too few studies to draw any general conclusions on whether feng shui is or is not useful for modern design practice. Even if there were more, it is unlikely that a general conclusion could ever be drawn. Feng shui as a system is simply too heterogeneous. Each theory or set of techniques (recommendations about water, greenery, qi flow, flying star, east-west system, etc.) should be explored more then once, preferably in different ways, at different times and with different (if possible large) test groups, preferably following a double-blind protocol. Only then could the individual systems in feng shui be properly evaluated. This has partly been done for the school of form. But if we can say, that the effects of its recommendations are similar with environmental psychology and sustainability, the question arises, why do we need feng shui at all, if its results are already embedded in modern design doctrine? One of the possible answers is that the greatest added value for the use of feng shui is to address the cultural sociological needs of the users. The value of feng shui tradition is well documented through social anthropological $^{\text {lviii }}$, economic ${ }^{\text {lix }}$ or medical anthropological ${ }^{\mathrm{lx}}$ research. What is the true value of these same recommendations in modern design, without this cultural and social framework, remains an open question. Based on this research and 20 years of personal experience in the dealing with feng shui studies and projects I summarize that there is (for now) no convincing data to suggest that the use of feng shui recommendations (meaning those with proven positive effects) yields significantly different design results than the one that we get if we follow a competent design practice, with an emphasis on the findings of environmental psychology and sustainability. However, exposure to these same criteria through feng shui can also have a positive educative effect. In real life, contemporary buildings do not always reflect the best of what the architectural profession has to offer. Also because of ignorance. Through studying feng shui or other traditional construction practices, we can become more attentive to the sustainable or psychological aspects of the design of physical space, which otherwise remain overlooked or in the background.

Finally, there is another aspect to be noted. In the evaluation of feng shui research, one of the fundamental concepts of feng shui, namely the concept of life energy qi, remains poorly researched. It can simply be ignored, or it can be used as an inspiration to reflect on the potential of the life potency of the physical space. Based on personal self-participative experience (methodologically based in social psychology, sociology and common-sense psychology ${ }^{1 x i}$ ), I argue that it is possible to perceive the elements or potential of the life potency of the physical space. But my perceptions of the life potency of the physical space are mainly not consistent with what feng shui theory teaches. This difference between theory and perceived field experience was also one of the reasons for the in-depth scientific analysis of the effectiveness of feng shui recommendations. At the same time, I can not deny the concept of the life potency of the physical space, precisely because of these same perceptions. Alexander discusses the life potency of the physical space in depth in his work Nature of Order $(2002 \mathrm{a}, 2002 \mathrm{~b}, 2004,2005)^{\text {lxii }}$, which, by the way, makes no mention of either feng shui or traditional Chinese philosophical concepts. The results of his research show that every space has the life potential, which can be manifested through proper design and thus felt in physical space. In this context, I conclude that the greatest potential of feng shui for contemporary architecture (based on what is known through research at the moment) is not so much in the practical application of its techniques and recommendations, as much of this is already included in everyday design practise, but in its philosophical and conceptual foundations. They encourage architects to re-think spatial concepts and, if necessary, to change established spatial paradigms. They encourage us to ask questions such as: 'How do I design a house if the house is a living organism inserted into a living landscape?' And by looking for answers to this and similar questions we can look for new, potentially more holistic solutions.

\section{REFERENCE}


${ }^{\mathrm{i}}$ Feng shui (1999): »Feng shui«, Haeuser, 6, 10-11.

${ }^{i i}$ See e.g. Wu, W. Y., Yau, O. H. M., Lu, H. Y. (2012): »Feng Shui Principles in Residential Housing Selection«, Psychology \& Marketing, 29, 7, 502 - 518; Peng, Y. S., Hsiung, H. H., Chen, K. H. (2012): « The Level of Concern about Feng Shui in House Purchasing: The Impacts of Self Efficacy, Superstition and the Big Five Personality Traits«, Psychology \& Marketing, 29, 7, 519 - 530; So, A. T. P., Lu, J. W. Z. (2001): »Natural ventilation Design by Computational Fluid Dynamics - A Feng-shui Approach«, Architectural Science Review, 44, 1, 61 - 69.

iii Bruun, O. (2008): An Introduction to Feng Shui. Cambridge, Cambridge University Press.

iv Paton, M. (2007): »Fengshui: A Continuation of 'Art of Swindlers'?«, Journal of Chinese Philosophy, $34,3,427$ - 445. Available at: https://onlinelibrary.wiley.com/doi/abs/10.1111/j.1540-6253.2007.00427.x (30.11.2018)

${ }^{v}$ See note 3 .

${ }^{v i}$ Paton, M. (2009): »Feng Shui the Energy of the Land«, in Mak, M. Y.,So, A. T. (ed) (2009): Research in Scientific Feng Shui and the Built Environment, City University of Hong Kong Press, 45 - 64.

${ }^{\text {vii }}$ See note 3 .

viii See e.g. Yu in Moran, E., Yu, J., Biktashev, V. (2005): »The complete Idiot's guide to Feng Shui«. New York, Third edition.Alpha books.

${ }^{\text {ix }}$ Chan, W. T. (1963): A Source Book in Chinese Philosophy. New Jersey, Princeton University Press in Mak, M. Y., So, A. T. (2011): Scientific Feng Shui for the Built Environment. Hong Kong, City University of Hong Kong Press: 29.

${ }^{x}$ Lip published one of the first feng shui manuals in 1979: Lip, E. (1979): Chinese Geomancy. Singapore, Times Books International.

${ }^{x i}$ Bramble, C. (2003): Architect's guide to feng shui. Oxford, Architectural press.

${ }^{\text {xii }}$ See e.g. Yan, X., Lu, F., Jiang, H., Wu, X., Cao, W., Xia, Z., Wang, J., Shen, H., Dao, M., Lin, H., Zhu, R. (2002): »Certain Physical Manifestation and Effects of External Qi of Yan Xin Life Science Technology«, Journal of Scientific Exploration, 16, 3, 381 - 411; Yan, X., Shen, H., Jiang, H. in Zhang, C. (2006): »External Qi of Yan Xin Qigong Differentially regulates the Akt and Extracellular Signal Regulated Kinase Pathways and is Cytotoxic to Cancer Cells but not to Normal Cells«, Journal of Biochemistry \& CellBiology, 38, 12, $2102-2113$.

${ }^{x i i i}$ Lu, Z. (1997): Scientific Qigong Exploration: The Wonders and Mysteries of Qi. Malvern, Pennsylvania, Amber Leaf Press.

${ }^{\text {xiv }}$ Matthews, M. (2019): Feng Shui: Teaching about Science and Pseudoscience. Springer International Publishing: 288.

${ }^{x v}$ See e.g. Shermer, M. (ed.), Linse, P. (cont.ed.) (2002): The Skeptic Encyclopedia of Pseudoscience. Santa Barbara, ABC-CLIO.

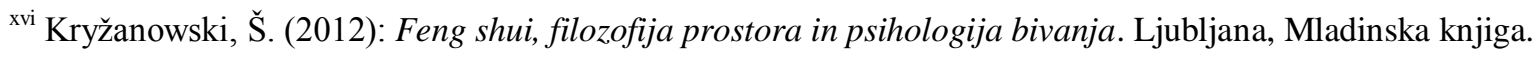

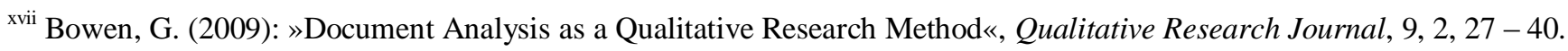

xviii Juneja, P. (2020): »Desk Research - methodology and Techniques «. Available at: https://www.managementstudyguide.com/desk-research.htm (Accessed 15.9.2020)

${ }^{\text {xix }}$ Creswell, J. W. (2009): Research Design: Qualitative, quantitative and Mixed Methods Approaches. Los Angeles, SAGE

${ }^{x x} \mathrm{Xu}$, Z. (2004): »Geomancy Theories and Bahavior Psychology«, Journal of Hefei University of Technology (Social Sciences). Available at: http://en.cnki.com.cn/Article_en/CJFDTOTAL (Accessed 1.3.2018).

${ }^{x x i}$ Bonaiuto, M., Bilotta, E., Stolfa, A. (2010): »Feng shui and Environmental Psychology: A Critical Comparison«, Journal of Architectural and Planning Research, 27, 1, 23 - 34.

xxii Kryžanowski, Š. (2019): »Comparative Analysis Between Selected Recommendations of Fengshui School of Form, Pattern Language of Alexander and Colleagues and Findings of Environmental Psychology", Urbani izziv, 30,2 , 124 - 134.

${ }^{x x i i i}$ Yoon, H. K. (1980): »The Image of Nature in Geomancy«, Geo Journal, 4, 4, 341 - 348. 
${ }^{\text {xxiv }}$ Shin, K. S., Lim, Y. H. (2013): »A Study on Passive Elements of Han - Ok on a Standpoint of Feng Shui Focused on the Old House of Yang Dong Twon«, Journal of the Architectural Institute of Korean Planning \& Design, 29, 12 - 20.

${ }^{x x v}$ Lau, S. S. Y., Garcia, R., Ou, Y., Kwok, M. M., Zhang, Y., Shen, S. J., Namba, H. (2005): »Sustainable Design and Its Simplest Form: Lessons from the Living Villages of Fujian Rammed Earth Houses”, Structural Survey, 2005, 23, $371-385$. Available at: https://hub.hku.hk/handle/10722/149372 (Accessed 28.2.2019)

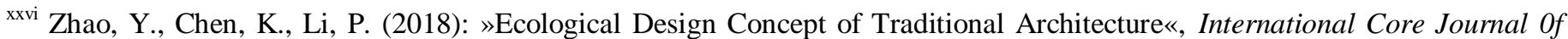
Engineering, 4, 4, $240-244$.

${ }^{\text {xxvii }}$ Choe, S. J., Han, S. H. (2019): Applicability of Feng Shui Thoughts for Sustainable Space Planning and Evaluation in Korea Verified Using Three-Dimensional Digital Mapping and Simulations«, Sustainability, 11, 20, 55 - 78.

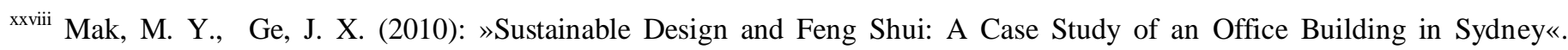
Available at: https://www.irbnet.de/daten/iconda/CIB_DC24655.pdf (Accessed 28. 2. 2019)

${ }^{\text {xxix }}$ Mak, M. Y., Ge, J. X. (2012): »Feng Shui: A Chinese Perspective of Sustainability«, Global Chinese Real Estate Congress Annual Conference, Macau. Available at: https://www.um.edu.mo/fba/gcrec2012/83974183/12203-Mak.pdf (Accessed_28. 2. 2019)

${ }^{x x x}$ Mak, M. Y. (2017): »An Empirical Study of Modern Sustainable Office Buildings in Sydney from the Feng Shui Perspective«, Academic Journal of Feng Shui, 1st Symposium Oceania, University of Technology Sydney, 13. - 14. maj 2017. Available at: http://ajofengshui.co.nf/wp-content/uploads/2017/06/Mak_Michael_2017_Empirical_Modern_Sustainable_L_PA.pdf (Accessed 28. 2. 2019)

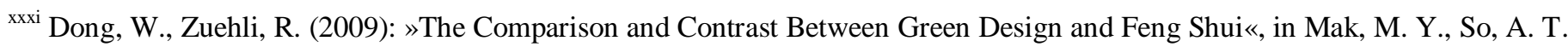
(ed) (2009): Research in Scientific Feng Shui and the Built Environment, City University of Hong Kong Press, 209 - 230.

${ }^{\text {xxxii }}$ Mak, M. Y., Hui, Y. (2018): »West Kowloon Station in Hong Kong: an exemplar case of sustainable Design and scientific Feng Shui Applications for High-speed rail Stations«, Academic Journal of feng Shui, 2, 1. Abstract available at: https://nova.newcastle.edu.au/vital/access/manager/Repository/uon:35578?view=null\&f0=sm_relation\%3A\%22Academic+Journa l+of+Feng+Shui+Vol.+2\%2C+Issue $+1 \% 22 \&$ sort=null (Accessed 15.9.2020)

xxxiii Octavia, L., Gunawan, T. (2014): »Feng shui in Modern House Design: Searching for the Rationale and Possible Impacts Assesment «, Journal of Architecture and Built Environment, 41, 1, 43 - 50.

xxxiv Spear, W. (1995): Feng Shui Made It Easy, Designing Your Live With the Ancient Art of Placement. Boston, Harper Collins Publishers.

${ }^{\text {xxxv }}$ Han, K. T., Amita, S. (1996): »An Empirical Study of Feng shui in Landscape«, Environments, 23, 3,36 - 49.

${ }^{x x x v i}$ Han, K. T. (2004): »A Preliminary Study of Luan Tou Feng shui Landscapes and Psychological Reactions«, Journal of Psychology in Chinese Societies, 5, 2, 289 - .

${ }^{\text {xxxvii } U m, ~ J . ~ S . ~(2009): ~ » E x p l o r i n g ~ S p a t i a l l y ~ P r i o r i t i z e d ~ P a r a m e t e r s ~ o f ~ F e n g-S h u i ~ f r o m ~ T o m b ~ F o o t p r i n t «, ~ I n t e r n a t i o n a l ~ J o u r n a l ~ o f ~}$ Geographical Information Science, 23, 4, 513 - 529.

xxxviii Lynch, E. S. (2003): Feng Shui as a Site Design Tool: Assessing Conditions of Human Comfort in Urban Places. Master's Theses, University of Arizona, Architecture and Landscape Architecture.

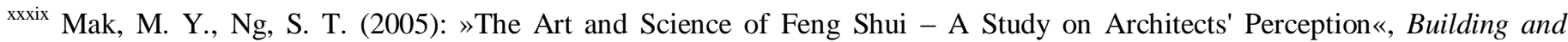
Environment, 40, 3, $427-434$.

${ }^{x l}$ Hong, W.T., Abdul-Rahman, H., Wang, C. (2017): »Are Feng shui Bedroom Rules Practical from the Architectural Perspective?« Academic Journal of Feng Shui, 1st Symposium Oceania, University of Technology Sydney, 13. - 14. maj 2017. Available at: http://ajofengshui.co.nf/wp-content/uploads/2017/05/Hong_Wan_Thing_2017_Bedroom_Rules_L_P.pdf (Accesed 1.3.2018).

${ }^{x l i}$ So, A. T. P., Lu, J. W. Z. (2001): »Natural ventilation Design by Computational Fluid Dynamics - A Feng-shui Approach«, Architectural Science Review, 44, 1, 61 - 69. 
xlii Kryžanowski, Š. (2019b): Feng Shui and Apperception of Space: An Overwiev of Scientific Research and a Filed Research of Efficiency of Recommendations. PhD dissertation. Ljubljana, ISH, Alma Mater Europaea, Institutum Studiorum Humanitatis Faculty of Postgraduate Humanities. (In Slovene)

xliii Kryžanowski, Š. (2021): »Impact of Feng Shui Bedrooms on Self-Assessed Sleep and Well-Being: A Randomized DoubleBlind Field Research with Instrumental Biocommunication. «South East European Journal of Architecture and Design, 1-8.

xliv Poulston, J., Bennett, R. (2012): »Feng Shui, Fact and Fiction: An Exploratory Study«. Available at: https://www.researchgate.net/profile/Jill_Poulston/publication/235260228_Fact_fiction_and_feng_shui_An_exploratory_study/lin ks/5669e80308ae62b05f027175/Fact-fiction-and-feng-shui-An-exploratory-study.pdf (Accessed 12.4.2018).

${ }^{x l v}$ See e.g. Ulrich, R. (1984): »View through a window may influence recovery from surgery«, Science, 224,420 - 421.

${ }^{x l v i}$ Bazley, C., Vink, P., Montgomery, J., Hedge, A. (2016): »Interior Effects on Comfort in Healthcare Waiting Areas«, Work, 54, $4,791-806$.

${ }^{x l v i i}$ Charles, R., Glover, S., Bauchmueller, K., Wood, D. (2017): »Feng shui And Emotional Response in the Critical care Environment (FARCE) study«, Anaesthesia, 72, 1528 - 1531.

xlviii Pheng, L. S., Xiaopeng, D., Ting, Q. L. (2012): »Assimilating Total Building Performance Mandates with Chinese Geomancy Principles and Scenarios«, Facilities, 30, 13/14, 558 - 589.

${ }^{x l i x}$ Chang, P. T., Lee, J. H., Hung, K. C., Tsai, J. T., Perng, C. (2009): »Applying Fuzzy Weighted Average Approach to Evaluate Office Layouts with Feng Shui Consideration«, Mathematical and Computer Modelling, 50, 1514 - 1537.

${ }^{1}$ See e.g. Wong, F. T. (2009): »An Assessment into the Basics of Eight Mansions Feng Shui Theory«, in Mak, M. Y., So, A. T. (ed) (2009): Research in Scientific Feng Shui and the Built Environment. Hong Kong, City University of Hong Kong Press, 27 44.

${ }^{\text {li }}$ See note 46 .

${ }^{\text {lii }}$ See note 37.

liii Bruun, O. (2003): Feng Shui in China, Geomantic Divination between State Orthodoxy and Popular Religion. Honolulu, University of Hawai Press.

liv See note 34 .

${ }^{\text {lv }}$ See note 46.

${ }^{\text {lvi }}$ See e.g. Augustin, S., 2009: Place advantage. Hoboken, New Jersey, Wiley\&Sons: 10.

${ }^{\text {lvii }}$ See e.g. Hwangbo, A. B. (1999): »A New Millennium and Feng Shui«, The Journal of Architecture, 4, 191 - 198.

lviii See note 53 .

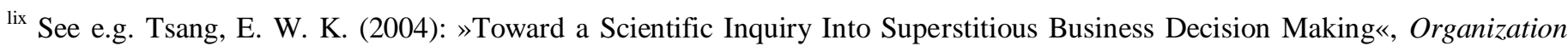
Studies. Dostopno prek: https://journals.sagepub.com/doi/abs/10.1177/0170840604042405 (23.3.2017); Chang, W. L. Lii, P. (2010): "Feng Shui and Its Role in Corporate Image and reputation: A Review From Business and Cultural Perspectives", Journal of Architecture and Planning Research, 27, 1, 1 - 13.

${ }^{\mathrm{lx}}$ See e.g. Yeo, S. S., Meiser, B., Barlow - Stewart, K., Goldstein, D., Tucker, K., Eisenbruch, M. (2004): »Understanding Comunnity Beliefs of Chinese Australians about Cancer: Initial Insights Using an Ethnographic Approach «, Psycho - Oncology, 14, 3, 174 - 186; Chui, Y. Y., Donoghue, J., Chenoweth, L. (2005): »Responses to Advanced Cancer: Chinese Australians«, Journal of Advanced Nursing, 52, 5, 498 - 507.

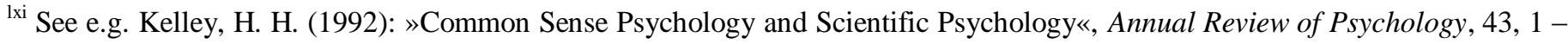
23.

Ixii Alexander, C. (2002a): The Phenomenon of Life - The Nature of Order, 1. Berkeley, Center for Environemntal Structure; 64. Alexander, C. (2002b): The Process of Creating Life - The Nature of Order, 2. Berkeley, Canter for Environmental Structure; Alexander, C. (2004): The Luminous Ground - The Nature of Order, 4. Berkeley, Canter for Environmental Structure; Alexander, C. (2005): A Vision of a Living World - The Nature of Order, 3. Berkeley, Canter for Environmental Structure 


\section{ABOUTH THE AUTHOR}

Špela Kryžanowski is an Assistant Professor for subject Feng Shui at Department for Interior Design (Faculty of Design, Associated Member of the University of Primorska, Slovenia). She is an architect by profession with a PhD in Humanities. She is engaged in Feng shui research in theory and practice for over 20 years. Contact mail: spela.kryzanowski@fd.si 